\title{
APLIKASI PENGGAJIAN GURU PADA MTS. AL-FURQON BANJARMASIN
}

\author{
${ }^{(1)}$ Dian Agustini, ${ }^{(2)}$ Muthia Farida \\ (1)(2)Teknik Informatika, Fakultas Teknologi Informasi, Universitas Islam Kalimantan \\ MAB \\ Jl. Adhiyaksa No. 2 Kayu Tangi, Banjarmasin \\ Email :dian.da989@gmail.com, muthiafarida59@yahoo.co.id
}

\begin{abstract}
Abstrak
Sistem informasi penggajian adalah sebuah program penggajian di dalam suatu pemerintah, lembaga atau instansi pendidikan, di mana program-program tersebut antara satu dengan lainnya saling berhubungan sehingga secara otomatis computer akan melakukan pengolahan terhadap data-data yang dimasukkan kedalam sistem. Penelitian dengan judul “ Aplikasi Penggajian Guru Pada Mts. Al-Furqon Banjarmasin ", di mana penelitian ini merupakan penelitian terapan. Tujuan dari penelitian ini adalah untuk memberikan solusi terhadap masalah yang terjadi berkaitan dengan sistem penggajian guru pada sekolah tersebut dan mempermudah pembuatan laporan penggajian guru. Metode yang digunakan penelitian ini adalah metode pengamatan langsung (survei), wawancara dan study pustaka. Selanjutnya melakukan analisis sistem dan perancangan desain sistem informasi penggajian yang dilanjutkan lagi dengan pembuatan sistem informasi penggajian. Hasil dari penelitian ini adalah sebuah aplikasi sistem informasi penggajian guru untuk memberikan kemudahan pada bendahara gaji ketika pembuatan laporan penggaji dan mengelola gaji guru.
\end{abstract}

Kata kunci: Aplikasi, Penggajian Guru, Sistem Informasi Penggajian

\begin{abstract}
Payroll information system is a payroll program within a government, institution or educational institution, where the programs are interconnected with one another so that the computer will automatically perform processing of the data entered into the system. The study under the title "Application of Teacher Payroll On Mts. Al-Furqon Banjarmasin ", where this research is an applied research. The purpose of this study is to provide solutions to problems that occur related to the teacher's salary system at the school and facilitate the preparation of teacher payroll reports. The method used in this research is the method of direct observation (survey), interview and literature study. Furthermore, perform system analysis and design of payroll information system design which is continued with the making of payroll information system. The result of this research is an application of teacher payroll information system to provide convenience to the treasurer of salary when making payroll report and manage teacher salary.
\end{abstract}

Keywords: Application, Teacher's salary, Payroll Information System. 


\section{PENDAHULUAN}

Dalam melakukan kegiatan pendidikannya sekolah tersebut ini masih menggunakan proses manual terutama pada proses penggajian guru dibagian honor. Dalam pengolahan datanya, bagian administrasi mengerjakannya masih bersifat manual. Ketika terjadi kesalahan dalam pencatatan dalam sebuah lembaga pendidikan terutama sekolah maka kegiatan operasional sekolah akan terganggu, akibatnya ada pihak yang merasa dirugikan. Terutama pada proses penggajian, sehingga menimbulkan data yang tidak akurat, dan tidak relevan, sehingga terjadi keterlambatan laporan.

\section{METODE PENELITIAN}

Metode Penelitian yang dipakai menggunakan Metode Eksperimen dengan Tahapan yang pertama adalah Tahap Pengumpulan Data. Beberapa tahapan dalam pengumpulan data yaitu ang pertama adalah Observasi (Pengamatan Langusng) yaitu Teknik pengumpulan data yang dilakukan dengan mengadakan pengamatan secara langsung terhadap sistem yang ada pada bagian Keuangan/Bendahara pada Mts. Al-Furqan Banjarmasin. Lalu yang kedua adalah Wawancara yaitu Teknik Pengumpulan data dengan cara berkomunikasi secara langsung dengan bendahara di Mts. Al-Furqan Banjarmasin. Dan yang ketiga adalah Studi Literatur yaitu teknik pengumpulan data dengan cara mereview jurnal-jurnal ilmiah, buku dan berbagai sumber refrensi yang terkait tentang penelitian yang akan dibuat.

Selanjutnya adalah Tahap Analisa Sistem yaitu merupakan kegiatan penguraian suatu sistem informasi yang utuh ke dalam beberapa bagian yang menuntut kita untuk melakukan identifikasi dan evaluasi terhadap permasalahan yang ada dan menentukan kebutuhan sistem dalam rangka mengusulkan perbaikan sistem.

Yang terakhir adalah Tahap Desain Sistem merupakan tahap setelah analisa sistem yang menentukan proses dan data yang diperlukan oleh sistem baru dengan tujuan untuk memenuhi kebutuhan kepada para pemakai, serta memberikan gambaran yang jelas dan rancang bangun yang lengkap kepada pemrogram komputer dan ahli teknik lain yang terlibat.

\section{HASIL DAN PEMBAHASAN}

Implementasi Sistem yang pertama adalah gambaran dari aplikasi atau program yang telah dibuat.

Halaman Log In

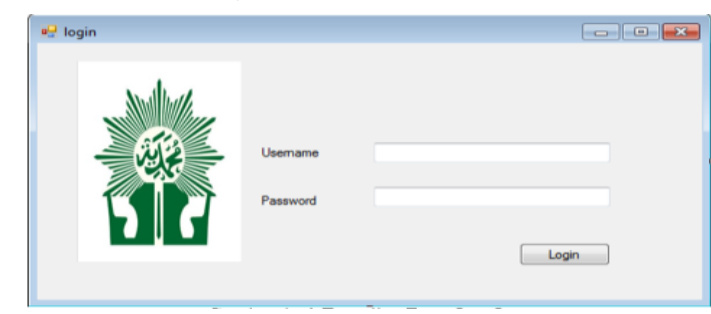

Menu ini berfungsi untuk mengakses menu selanjutnya dalam sistem. Cara mengakses menu ini adalah dengan input data username dan password yang sesuai dengan sistem. Tombol button login berfungsi untuk masuk kedalam aplikasi setelah user mengisi data username dan password yang sesuai.

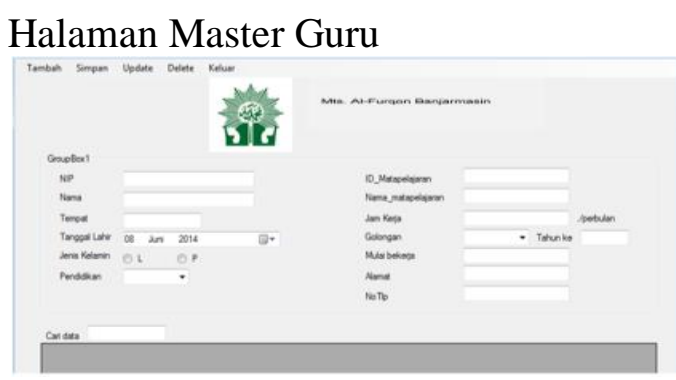

Dalam form data master guru berfungsi untuk memasukkan data para guru yang ada disekolah seperti Nip, Nama, Tempat Tanggal Lahir dan lain-lain. 
Halaman Master Kelas

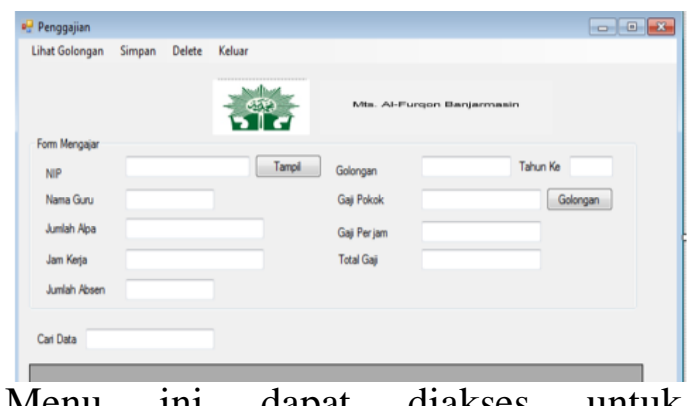

Menu ini dapat diakses untuk mengisikan jumlah data kelas yang ada Mts. Al-Furqon Banjarmasin.

Halaman Pencatatan Mata Pelajaran

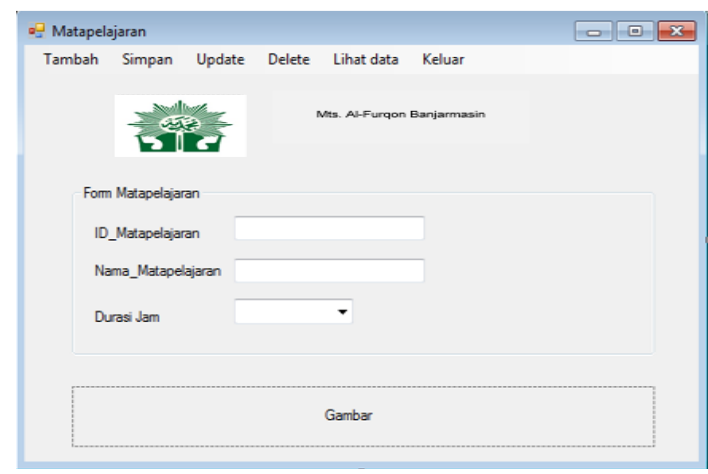

Menu ini dapat diakses untuk mengisi data mata pelajaran yang ada.

Halaman Transaksi Penggajian

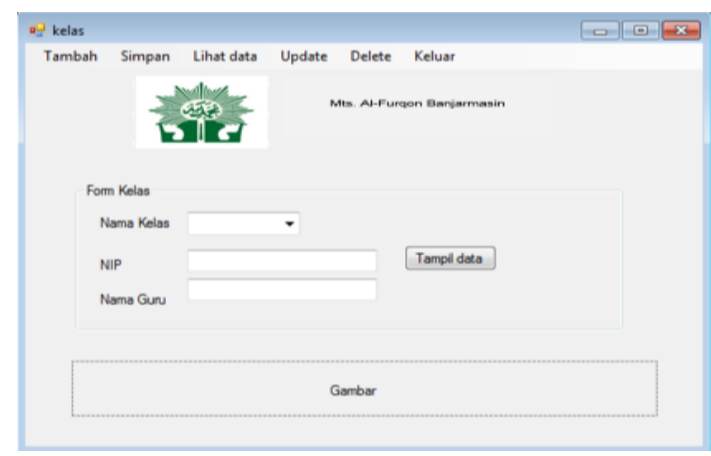

Menu ini dapat diakses untuk proses penggajian para guru yang ada di sekolah Mts. Al Furqon Banjarmasin.

Metode yang di gunakan dalam pengujian ini adalah menggunakan pengujian metode Black Box.
Rencana Pengujian Sistem

Pengujian perangkat lunak adalah elemen kritis dari jaminan kualitas perangkat lunak dan mempesentasikan kajian pokok dari spesifikasi, desain, dan pengkodean. Pengujian Black-box berfokus pada persyaratan fungsional perangkat lunak. Dengan demikian, pengujian blackbox memungkinkan perekayasa perangkat lunak mendapatkan serangkaian kondisi input yang sepenuhnya semua persyaratan fungsional untuk suatu program.

Rencana Pengujian Sistem

\begin{tabular}{|l|l|l|}
\hline \multicolumn{1}{|c|}{ Item Uji } & \multicolumn{1}{|c|}{ Detail Pengujian } & \multicolumn{1}{c|}{$\begin{array}{c}\text { Jenis } \\
\text { Pengujian }\end{array}$} \\
\hline Login & $\begin{array}{l}\text { Verivikasi login } \\
\text { Admin }\end{array}$ & Black Box \\
\cline { 2 - 3 } & Verifikasi login Staf & Black Box \\
\hline $\begin{array}{l}\text { Pengolahan } \\
\text { Data Guru }\end{array}$ & $\begin{array}{l}\text { Simpan, Ubah, } \\
\text { Hapus, Cari Data }\end{array}$ & Black Box \\
\hline $\begin{array}{l}\text { Pengolahan } \\
\text { Data Kelas }\end{array}$ & $\begin{array}{l}\text { Simpan, Ubah, } \\
\text { Hapus, Cari Data }\end{array}$ & Black Box \\
\hline $\begin{array}{l}\text { Pengolahan } \\
\text { Data Pelajaran }\end{array}$ & $\begin{array}{l}\text { Simpan, Ubah, } \\
\text { Henus, Cari Data }\end{array}$ & Black Box \\
\hline $\begin{array}{l}\text { Pengolahan } \\
\text { Data Transaksi } \\
\text { Gaji }\end{array}$ & $\begin{array}{l}\text { Simpan, Ubah, } \\
\text { Hapus, Cari Data }\end{array}$ & Black Box \\
\hline
\end{tabular}

Kasus dan Hasil Pengujian

Berdasarkan rencana pengujian yang telah disusun, maka dapat dilakukan pengujian sebagai berikut :

Pengujian Form Login

\begin{tabular}{|l|l|}
\hline 1. Login & Username, password \\
\hline $\begin{array}{l}\text { Data } \\
\text { Masukan }\end{array}$ & $\begin{array}{l}\text { Data login dimasukkan, isi username dan } \\
\text { isi password lalu klik tombol masuk } \\
\text { dilakukan proses pengecekan data login. } \\
\text { Apabila data login benar maka user dapat } \\
\text { menjalankan system }\end{array}$ \\
\hline Pengamatan & $\begin{array}{l}\text { Dapat mengisi data login sesuai dengan } \\
\text { yang diharapkan }\end{array}$ \\
\hline Kesimpulan & Sukses \\
\hline
\end{tabular}


Pengujian Form Data Guru

\begin{tabular}{|c|c|}
\hline \multicolumn{2}{|l|}{ 2. Guru } \\
\hline \multicolumn{2}{|r|}{ Simpan Data } \\
\hline Data Masukan & $\begin{array}{l}\text { Mengisi atribut data Siswa } \\
\text { yang telah disediakan } \\
\text { dengan benar }\end{array}$ \\
\hline $\begin{array}{l}\text { Yang } \\
\text { diharapkan }\end{array}$ & $\begin{array}{l}\text { Proses pemasukan data } \\
\text { berhasil, klik simpan, data } \\
\text { yang tersimpan dalam } \\
\text { database }\end{array}$ \\
\hline Pengamatan & $\begin{array}{l}\text { Data berhasil tersimpan } \\
\text { dalam database }\end{array}$ \\
\hline Kesimpulan & Sukses \\
\hline \multicolumn{2}{|r|}{ Edit Data } \\
\hline Data Masukan & $\begin{array}{l}\text { Mengubah atribut data } \\
\text { siswa yang sudah ada dalam } \\
\text { database }\end{array}$ \\
\hline $\begin{array}{l}\text { Yang } \\
\text { diharapkan }\end{array}$ & $\begin{array}{l}\text { Proses masukan data benar, } \\
\text { klik ubah dan data yang } \\
\text { sudah diubah masuk } \\
\text { kedalam database }\end{array}$ \\
\hline Pengamatan & $\begin{array}{l}\text { Data berhasil diubah dan } \\
\text { tersimpan dalam database }\end{array}$ \\
\hline Kesimpulan & Sukses \\
\hline \multicolumn{2}{|r|}{ Hapus Data } \\
\hline Data Masukan & $\begin{array}{l}\text { Menghapus atribut data } \\
\text { Siswa yang sudah ada dalam } \\
\text { database }\end{array}$ \\
\hline $\begin{array}{l}\text { Yang } \\
\text { diharapkan }\end{array}$ & $\begin{array}{l}\text { Klik hapus dan data } \\
\text { terhapus dalam database }\end{array}$ \\
\hline Pengamatan & $\begin{array}{l}\text { Data berhasil dihapus dalam } \\
\text { database }\end{array}$ \\
\hline Kesimpulan & Sukses \\
\hline \multicolumn{2}{|r|}{ Cari Data } \\
\hline Data Masukan & $\begin{array}{l}\text { Mengisi atribut data Siswa } \\
\text { yang akan dicari dengan } \\
\text { benar }\end{array}$ \\
\hline $\begin{array}{l}\text { Yang } \\
\text { diharapkan }\end{array}$ & $\begin{array}{l}\text { Proses pencarian data } \\
\text { berhasil }\end{array}$ \\
\hline Pengamatan & $\begin{array}{l}\text { Data berhasil dicari dalam } \\
\text { database }\end{array}$ \\
\hline Kesimpulan & Sukses \\
\hline
\end{tabular}

Pengujian Form Data Pengalaman

Terakhir Pelamar

\begin{tabular}{|l|l|}
\hline \multicolumn{2}{|l|}{ Kasus dan Hasil Uji } \\
\hline Simpan Data \\
\hline Data Masukan & $\begin{array}{l}\text { Mengisi atribut data } \\
\text { pengalaman terakhir } \\
\text { pelamar yang telah } \\
\text { disediakan dengan benar }\end{array}$ \\
\hline $\begin{array}{l}\text { Yang } \\
\text { diharapkan }\end{array}$ & $\begin{array}{l}\text { Proses pemasukan data } \\
\text { berhasil, klik simpan, data } \\
\text { yang tersimpan dalam } \\
\text { database }\end{array}$ \\
\hline Pengamatan & $\begin{array}{l}\text { Data berhasil tersimpan } \\
\text { dalam database }\end{array}$ \\
\hline Kesimpulan & Sukses \\
\hline
\end{tabular}

\begin{tabular}{|c|c|}
\hline \multicolumn{2}{|l|}{ Ubah Data } \\
\hline Data Masukan & $\begin{array}{l}\text { Mengubah atribut data } \\
\text { pengalaman terakhir } \\
\text { pelamar yang sudah ada } \\
\text { dalam database }\end{array}$ \\
\hline $\begin{array}{l}\text { Yang } \\
\text { diharapkan }\end{array}$ & $\begin{array}{l}\text { Proses masukan data } \\
\text { benar, klik ubah dan data } \\
\text { yang sudah diubah masuk } \\
\text { ke dalam database }\end{array}$ \\
\hline Pengamatan & $\begin{array}{l}\text { Data berhasil diubah dan } \\
\text { tersimpan dalam database }\end{array}$ \\
\hline Kesimpulan & Sukses \\
\hline \multicolumn{2}{|l|}{ Hapus Data } \\
\hline Data Masukan & $\begin{array}{l}\text { Menghapus atribut data } \\
\text { pengalaman terakhir } \\
\text { pelamar yang sudah ada } \\
\text { dalam database }\end{array}$ \\
\hline $\begin{array}{l}\text { Yang } \\
\text { diharapkan }\end{array}$ & $\begin{array}{l}\text { Klik hapus dan data } \\
\text { terhapus dalam database }\end{array}$ \\
\hline Pengamatan & $\begin{array}{l}\text { Data berhasil dihapus } \\
\text { dalam database }\end{array}$ \\
\hline Kesimpulan & Sukses \\
\hline \multicolumn{2}{|l|}{ Cari Data } \\
\hline Data Masukan & $\begin{array}{l}\text { Mengisi atribut data } \\
\text { pengalaman terakhir } \\
\text { pelamar yang akan dicari } \\
\text { dengan benar }\end{array}$ \\
\hline $\begin{array}{l}\text { Yang } \\
\text { diharapkan }\end{array}$ & $\begin{array}{l}\text { Proses pencarian data } \\
\text { berhasil }\end{array}$ \\
\hline Pengamatan & $\begin{array}{l}\text { Data berhasil dicari dalam } \\
\text { database }\end{array}$ \\
\hline Kesimpulan & Sukses \\
\hline
\end{tabular}

Pengujian Form Data Kelas

\begin{tabular}{|l|l|}
\hline \multicolumn{2}{|c|}{ 3. Data Kelas } \\
\hline Data Masukan & $\begin{array}{l}\text { Mengisi atribut data } \\
\text { Guru yang telah } \\
\text { disediakan dengan } \\
\text { benar }\end{array}$ \\
\hline Yang diharapkan & $\begin{array}{l}\text { Proses pemasukan } \\
\text { data berhasil, klik } \\
\text { simpan, data yang } \\
\text { tersimpan dalam } \\
\text { database }\end{array}$ \\
\hline Pengamatan & $\begin{array}{l}\text { Data berhasil } \\
\text { tersimpan dalam } \\
\text { database }\end{array}$ \\
\hline Kesimpulan & Sukses \\
\hline Edit & $\begin{array}{l}\text { Data } \\
\text { Dengubah atribut } \\
\text { data Guru yang sudah } \\
\text { ada dalam database }\end{array}$ \\
\hline Yang diharapkan & $\begin{array}{l}\text { Proses masukan data } \\
\text { benar, klik ubah dan } \\
\text { data yang sudah } \\
\text { diubah masuk } \\
\text { kedalam database }\end{array}$ \\
Data berhasil diubah \\
\hline Pengamatan
\end{tabular}


p-ISSN 2502-4922,e-ISSN 2615-0867

\begin{tabular}{|l|l|}
\hline & $\begin{array}{l}\text { dan tersimpan dalam } \\
\text { database }\end{array}$ \\
\hline Kesimpulan Hapus Data \\
\hline Data Masukan & $\begin{array}{l}\text { Menghapus atribut } \\
\text { data Guru yang sudah } \\
\text { ada dalam database }\end{array}$ \\
\hline Yang diharapkan & $\begin{array}{l}\text { Klik hapus dan data } \\
\text { terhapus dalam } \\
\text { database }\end{array}$ \\
\hline Pengamatan & $\begin{array}{l}\text { Data berhasil dihapus } \\
\text { dalam database }\end{array}$ \\
\hline Kesimpulan & Sukses \\
\hline \multicolumn{2}{|c|}{ Cari Data } \\
\hline Data Masukan & $\begin{array}{l}\text { Mengisi atribut data } \\
\text { Guru yang akan } \\
\text { dicari dengan benar }\end{array}$ \\
\hline Yang diharapkan & $\begin{array}{l}\text { Proses pencarian data } \\
\text { berhasil }\end{array}$ \\
\hline Pengamatan & $\begin{array}{l}\text { Data berhasil dicari } \\
\text { dalam database }\end{array}$ \\
\hline Kesimpulan & Sukses \\
\hline
\end{tabular}

Pengujian Data Transaksi Gaji

\begin{tabular}{|c|c|}
\hline \multicolumn{2}{|c|}{ 4. Transaksi Penggajian } \\
\hline \multicolumn{2}{|c|}{$\begin{array}{r}\text { Simpan Data } \\
\end{array}$} \\
\hline Data Masukan & $\begin{array}{l}\text { Mengisi atribut data } \\
\text { Nilai Siswa yang telah } \\
\text { disediakan dengan } \\
\text { benar }\end{array}$ \\
\hline Yang diharapkan & $\begin{array}{l}\text { Proses pemasukan data } \\
\text { berhasil, klik simpan, } \\
\text { data yang tersimpan } \\
\text { dalam database }\end{array}$ \\
\hline Pengamatan & $\begin{array}{l}\text { Data berhasil } \\
\text { tersimpan dalam } \\
\text { database }\end{array}$ \\
\hline Kesimpulan & Sukses \\
\hline \multicolumn{2}{|c|}{ Edit Data } \\
\hline Data Masukan & $\begin{array}{l}\text { Mengubah atribut data } \\
\text { Nilai siswa yang sudah } \\
\text { ada dalam database }\end{array}$ \\
\hline Yang diharapkan & $\begin{array}{l}\text { Proses masukan data } \\
\text { benar, klik ubah dan } \\
\text { data yang sudah } \\
\text { diubah masuk kedalam } \\
\text { database }\end{array}$ \\
\hline Pengamatan & $\begin{array}{l}\text { Data berhasil diubah } \\
\text { dan tersimpan dalam } \\
\text { database }\end{array}$ \\
\hline Kesimpulan & Sukses \\
\hline \multicolumn{2}{|c|}{ Hapus Data } \\
\hline Data Masukan & $\begin{array}{l}\text { Menghapus atribut } \\
\text { data Nilai Siswa yang } \\
\text { sudah ada dalam } \\
\text { database }\end{array}$ \\
\hline Yang diharapkan & $\begin{array}{l}\text { Klik hapus dan data } \\
\text { terhapus dalam } \\
\text { database }\end{array}$ \\
\hline
\end{tabular}

\begin{tabular}{|l|l|}
\hline Pengamatan & $\begin{array}{l}\text { Data berhasil dihapus } \\
\text { dalam database }\end{array}$ \\
\hline Kesimpulan & Sukses \\
\hline Cari Data \\
\hline Data Masukan & $\begin{array}{l}\text { Mengisi atribut data } \\
\text { Nilai Siswa yang akan } \\
\text { dicari dengan benar }\end{array}$ \\
\hline Yang diharapkan & $\begin{array}{l}\text { Proses pencarian data } \\
\text { berhasil }\end{array}$ \\
\hline Pengamatan & $\begin{array}{l}\text { Data berhasil dicari } \\
\text { dalam database }\end{array}$ \\
\hline Kesimpulan & Sukses \\
\hline
\end{tabular}

\section{KESIMPULAN}

Pengolahan data dengan menggunakan sebuah sistem mendapatkan hasil yang optimal, berdasarkan data yang telah diinputkan ke dalam sistem tersebut dan penggunaan perangkat komputer yang baik dapat menghasilkan hasil yang lebih maksimal dalam pengoperasian program.

\section{REFERENSI}

[1] Bastian, indra, 2006, Akuntansi Pendidikanb, Erlangga, Jakarta

[2] Fathansyah, 2001, Teks Ilmu Komputer Basis Data, CV. Informatika, Bandung

[3] Jayanti, Dwi, Sistem Informasi Penggajian Pada CV.Blumbungan Sejati Pacitan, Indonesia Jurnal On Computer Science Speed (IJCSS), ISSN 1979-9330, ijcss.unsa.ac.id, Desember 2013

[4] Jogiyanto, 2005, Analisis dan Desain Sistem Informasi : Pendekatan terstruktur Teori dan Praktek Aplikasi Bisnis, Andi Offet, Yogyakarta

[5] Lucas, Henry, 1993, Analisis Desain dan Implementasi Sistem Informasi, Erlangga, Jakarta

[6] McLeod, 1996, Sistem Informasi Manajemen, PT. Prenhallindo, Jakarta 